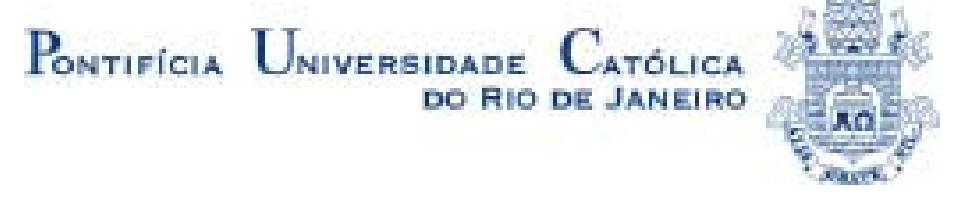

Bianca Winograd

\begin{abstract}
Mulheres Guerreiras em comunidades Pobres - Uma luta pela cidadania.
\end{abstract}

Dissertação apresentada como requisito parcial para obtenção do grau de Mestre pelo Programa de Pós-graduação em Serviço Social do Departamento de Serviço Social da PUC-Rio

Orientadora: Ilda Lopes Rodrigues da Silva

Rio de Janeiro Maio de 2006 


\title{
Bianca Winograd
}

Mulheres Guerreiras em comunidades
Pobres - Uma luta pela cidadania.

Dissertação apresentada como requisito parcial para obtenção do grau de Mestre pelo Programa de Pós-graduação em Serviço Social do Departamento de Serviço Social do Centro de Ciências Sociais da PUC-Rio. Aprovada pela Comissão Examinadora abaixo assinada.

\author{
Profa. Ilda Lopes Rodrigues da Silva \\ Orientadora \\ Departamento de Serviço Social- PUC - Rio
}

Profa. Sonia Maria Giacomini

PUC-Rio

Profa. Suely Gomes Costa UFF

Prof. João Pontes Nogueira Vice Decano de Pós-Graduação do Centro de Ciências Sociais PÜC-Rio

Rio de Janeiro, 30 de maio de 2006 
Todos os direitos reservados. É proibida a reprodução total ou parcial do trabalho sem autorização da universidade, da autora e do orientador.

\section{Bianca Winograd}

Graduou-se em Psicologia na USU (Universidade Santa Úrsula) em 2003. Foi bolsista de Iniciação Científica pela Fundação de Amparo à Pesquisa do Estado do Rio de Janeiro no Projeto "Jovens, Mídia e Novas Tecnologias". Participou junto com o CIESPI e a PUC - Rio em outros projetos na área social, como "Mulheres em Ação", o Curso para Lideranças Comunitárias, este junto ao CCE (Centro de Cursos de Extensão) da PUC-Rio.

Ficha Catalográfica

Winograd, Bianca

Mulheres guerreiras em comunidades pobres - uma luta pela cidadania / Bianca Winograd ; orientadora: Ilda Lopes Rodrigues da Silva. - Rio de Janeiro : PUC-Rio, Departamento de Serviço social, 2006.

$132 \mathrm{f.} ; 30 \mathrm{~cm}$

Dissertação (mestrado) - Pontifícia Universidade Católica do Rio de Janeiro, Departamento de Serviço social.

Inclui bibliografia

1. Serviço social - Teses. 2. Genero. 3. Mulheres História. 4. Cidadania. 5. Direitos sociais. I. Silva, Ilda Lopes Rodrigues da. II. Pontifícia Universidade Católica do Rio de Janeiro. Departamento de Serviço social. III. Título. 


\title{
Agradecimentos
}

\author{
À minha orientadora Professora Ilda Lopes Rodrigues da Silva pelo estímulo e \\ parceria para a realização do trabalho.
}

Ao pessoal do CIESPI, em especial às Professoras Irene Rizzini e Maria Helena Zamora.

Ao CNPQ e a PUC-Rio, pelos auxílios concedidos, sem os quais este trabalho não poderia ter sido realizado.

Ao meu marido Marcelo por todo apoio, paciência e compreensão.

Aos meus filhos Marcus Vinicius, Hannah e Isabella pela cessão do tempo.

Aos meus pais, Fany e Rubem, pela educação, atenção e carinho.

A todos os amigos e familiares que de uma forma ou de outra me estimularam ou me ajudaram. 


\section{RESUMO}

Winograd, Bianca; Silva, Ilda Rodrigues Lopes. Mulheres guerreiras em comunidades pobres - Uma luta pela cidadania. Rio de Janeiro, 2006. 132 p. Dissertação de Mestrado - Departamento de Serviço Social, Pontifícia Universidade Católica do Rio de Janeiro.

Este estudo visa mostrar que a experiência de mulheres pobres e anônimas que se destacam por trabalhos sociais em suas comunidades pode nos revelar várias questões plurais dentro de um conjunto supostamente homogêneo. As mulheres escolhidas neste estudo se destacaram através da resistência individual, ou por não se submeter aos padrões sociais que tentam impedir sua inserção em espaços supostamente privilegiados, e da persistência em fazer de trabalhos sociais um caminho de luta rumo à conquista plena de seus direitos enquanto cidadãs. Talvez, ao final deste estudo, se consiga contribuir com a história social das Mulheres no Brasil. O jogo social de consentimentos e conflitos invisíveis que aparece na luta de poder entre as próprias mulheres raramente é exposto como nessa oportunidade em que mulheres pobres e faveladas têm de contar sua história. Para além da visão clássica da condição feminina que uniformiza mulheres e homens, este estudo pretende mostrar os deslocamento destas posições dicotômicas de gênero que englobam questões de raça / etnia, classe e geração.

\section{Palavras-Chave}

Gênero; história das mulheres; cidadania; direitos sociais. 


\section{ABSTRACT}

Winograd, Bianca; da Silva, Ilda Rodrigues Lopes (Advisor) Warrior Women in Poor Communities - A Struggle toward Citizenship Rights. Rio de Janeiro, 2006. 132 p. MSc Dissertation - Departamento de Serviço Social, Pontifícia Universidade Católica do Rio de Janeiro.

This study doesn't seek to portray histories of heroines and of executioners, but show that the women's experience can reveal us several plural subjects of a group supposedly homogeneous. The chosen women in this study, got if it highlights through the individual resistance in not submitting to the effective social patterns that try to impede their inserts supposedly in spaces privileged and of the persistence in doing a fight road of their social works heading for the full conquest of their rights while citizens. Maybe, at the end of this study, I get to contribute with the social history of the Women in Brazil putting in prominence the social game of consents and invisible conflicts that appear in the fight of power also among the own women, because rarely, the poor and slum dwellers women have the opportunity to count their history. For besides the classic vision of the feminine condition that it equalizes women and men, this study intends to show the displacement of these divided positions gender that include race / ethno, class and generation.

\section{Keywords}

Gender; women's history; citizenship; social rights. 


\section{SUMÁRIO}

INTRODUÇÃO 08

CAPÍTULO 1. A VISIBILIDADE DAS MULHERES 28

1.1. A Questão de Gênero 28

1.2. História das Mulheres 36

CAPÍTULO 2. FEMINILIZAÇÃO DA POBREZA

2.1. O Papel das Mulheres 43

2.2. Feminismos - Mulheres Fazendo a História 53

CAPÍTULO 3. CIDADANIA DAS MULHERES E IGUALDADE DE GÊNERO 68

3.1. Conceituação e Legislação 68

3.2. Cidadania e Minorias 76

CAPÍTULO 4. MULHERES GUERREIRAS EM COMUNIDADES POBRES: UMA LUTA PELA CIDADANIA 85

4.1. Vida Familiar 86

4.2. Mundo do Trabalho 90

4.3. Questões de Gênero 98

4.4. Ação Social / Cidadania 103

4.5. Vida na Comunidade 109

4.6. Visão de Futuro 112

$\begin{array}{ll}\text { CONCLUSÃO } & 115\end{array}$

REFERÊNCIAS BIBLIOGRÁFICAS 124 